\title{
Towards an Asian Structured Cable Planning Model
}

\author{
Peter Dell \\ Curtin University of Technology \\ GPO Box U1987 Perth, Western Australia, 6845 \\ Tel: +61-8-9266-4485 \\ Fax: +61-8-9266-3076 \\ E-mail: peter.dell@cbs.curtin.edu.au
}

\begin{abstract}
Organisations may find themselves having to replace cabling after a relatively short period if subsequent communications technologies do not operate over the installed media, resulting in costly disruption. Difficulties predicting which media will be dominant in the future are exacerbated because copper, fibre, and wireless all currently have their proponents.
\end{abstract}

This research identifies factors that will form the basis of a statistical model that could be used to improve media selection decision-making. Further research to develop this model is outlined.

\section{ACKNOWLEDGEMENTS}

The author would like to thank George Low for collecting the survey data analysed in this paper, to Network Computing Asia for hosting and promoting the survey, and to HellermannTyton for sponsoring the survey. Thanks also to Michael Barker and Ashley Lloyd for feedback on draft copies of this paper. Finally, the author would like to thank an anonymous reviewer for identifying confusion regarding the way applications affect cable selection. 


\section{INTRODUCTION}

Structured cabling is that which is embedded within a building and connects network devices around the building together. Such cabling is typically enclosed within cable ducts in a building's ceiling space, and runs through walls and risers between floors. The backbone connects different wiring closets and floors of the building together, and is sometimes referred to as vertical cabling (Clark, 2002). Horizontal cabling is that which connects network devices to the backbone, and normally ends at a plate in the wall. A short cable from the network device to the wall plate completes the connection (Vacca, 1999).

As structured cabling is contained within the building, its installation is costly and disruptive. It is perhaps because of this that cabling can be made to last up to 10 years before obsolescence (Qayoumi, 1995), maybe even up to 15 years (Phan, 2001) - a long time when compared to other IT infrastructure such as computer hardware and software. However, aside from legacy issues arising from having such a long lifespan, getting the physical layer right is also important when considering that it can be the source of considerable on-going costs if poorly installed. Inverso (2001) reports that nearly half of all network faults are the result of poor cabling. Groth et al. (2001) put the figure at nearly $70 \%$, and suggest that the physical layer is the most neglected aspect of computer network design.

Cable can be either copper wire or fibreoptic, and there is a range of cables available. The most common copper cables in use today are Enhanced Category 5 (Cat5e), and Category 6 (Cat6). Category 7 (Cat7) is also available but not yet widespread. Older installations may be of Category 3 (Cat3). Copper cable is cheaper and easier to install, and although technological developments sometimes confuse the issue, copper cable is slower than fibreoptic cable as distance increases.

Fibre can be categorised according to two main types, single-mode and multimode. Single mode, while more expensive, is widely used for transmission over longer distances (Tanenbaum, 2003). Multimode fibre can be further divided into two categories based on its diameter, with 50 micron and 62.5 micron being the two most popular sizes in use. 
Single mode fibre carries a single signal, usually emitted from a laser light source, while multimode fibre carries multiple signals, often emitted from LEDs rather than lasers. This research is concerned purely with the cable type; encoding techniques and data link technologies are not included in the analysis.

Currently there is no clear industry favourite cable. Cat6, Cat7, single-mode fibre, and 50 micron and 62.5 micron multimode fibre all have their supporters. Thus, any organisation installing infrastructure cabling is faced with the dilemma that the investment they are about to make will remain for up to 15 years, but the IT industry currently has no clear opinion to guide such a decision.

The importance of using a widespread cabling medium is especially clear when one considers such longevity in conjunction with the well-documented impact of downstream products on competition among upstream products (Choi and Whinston, 2000). If a building is wired with cabling that does not support widely available future technologies, future tenants of such a building will have three options.

The first option would be to continue using older, increasingly obsolete communications devices. Alternatively, the cabling could be replaced, but as "nothing is worth recabling your building", and because "you'd have to be nuts to rip out your cable plant unless you had a really good reason" (Feldman, 2001), this is not a desirable option. Third, communications equipment can be selected from future technologies of only limited availability. None of these options are desirable, and avoiding the problem in the first place is preferable. Thus, organisations installing structured cabling systems should do so using cable that is likely to be supported in the future.

This is the issue being explored by the current research. The objective is to develop a model to help minimize the risk in infrastructure decision making for Asian organisations, thus resulting in a more efficient Asian IT industry as a whole. A statistical model can be developed to explain cable selection behaviour, based on the following: 
- Which factors influence cable selection

- Relationships between different factors influencing the cable selection process

- The outcome of that process

Such a model could then be used to better predict future cable adoption. Its development will lead to improved decision-making in two ways. Firstly, in developing the model the research has provided a snapshot of current cabling selection practices in Asian organisations, informing those organisations making decisions on cabling in the shortterm.

Secondly, the model can then be used to better predict future cable adoption. While trying to predict what cabling types will be dominant 10 to 15 years into the future seems an impossible task, and 100\% accurate prediction will never be possible. However, if even a fraction of decisions are improved, this will add up to significant increases in efficiency, given that almost every organisation of at least moderate size uses such technology.

\section{PILOT STUDY}

Exploratory data have been collected from a survey of IT professionals (Low, 2003). Invitations to complete the survey were sent to subscribers of Network Computing Asia, a popular network computing web magazine, attracting 371 responses. The survey was also promoted on the Network Computing Asia website, and a prize was offered in order to boost response rates.

The survey attracted responses from 14 countries, however most were from Asia, with $80 \%$ coming from Singapore, Malaysia and Hong Kong. Responses were collected from small to large companies; $23.7 \%$ of responses were from companies with an annual IT budget below $\$ 50 \mathrm{k}, 24.8 \%$ of responses were from companies with an annual IT budget between $\$ 50 \mathrm{k}$ and $\$ 100 \mathrm{k}, 22.9 \%$ of responses from companies with an annual IT budget between $\$ 100 \mathrm{k}$ and $\$ 500 \mathrm{k}$, and $28.6 \%$ of responses from companies with an annual IT budget greater than $\$ 500 \mathrm{k}$. 
The size of respondents' networks, indicated by the number of network points in use, also varied in size; $20.5 \%$ of responses reported 50 points or less, $15.1 \%$ of responses fell between 51 and 100 points, 16.4\% were between 101 and 200 points, 17.3\% were between 201 and 500, and 30.7\% reported more than 500 points.

Interviews with three consultants in the Australian IT industry were also conducted to determine whether conclusions based on the survey data were plausible. Two interviews were conducted in person and the third was conducted via phone and e-mail. The possibility of differences between the survey sample and that of the interviews is noted, and should be addressed in further research.

\section{ANALYSING SURVEY RESPONSES}

The survey responses revealed a number of relationships between factors surrounding organisations' implementation of vertical and horizontal media. While not conclusive, they may provide insight into areas that can be examined further, with the goal of understanding how organisations select infrastructure cabling.

Associative relationships were identified between pairs of variables using lambda $(\lambda)$ tests on nominal data. Lambda is a proportional reduction in error measure; it indicates the proportion by which error is reduced in a prediction of a dependent variable, given the state of the independent variable (Norušis, 1997). Given the objective of this research is reducing the error in predicting the types of cable in widespread use in the future, lambda tests are appropriate.

If a symmetric lambda test is used and determines a relationship, either variable can be used to predict the other. If an asymmetric test is used, it is only possible to predict the dependent variable given the independent variable. Lambda values range from 0 to 1 , and the higher the value the stronger the relationship between the two variables. The significance level used was a strict $0.5 \%(\alpha=0.005)$.

Results where the required significance was not met $(\mathrm{p}>0.005)$ were discarded, as were weak associations where $\lambda<0.100$. Significant results are discussed below. 
The strongest relationship revealed is between the implementation of vertical and horizontal fibre cabling. When the implementation of horizontal cabling is the dependent variable, $\lambda=0.398(\mathrm{p}=0.000)$, and when implementation of vertical cabling is the dependent variable, $\lambda=0.322(\mathrm{p}=0.000)$. Organisations thus have a strong tendency to implement vertical and horizontal fibreoptic cabling at the same time. It should be noted that this result does not distinguish between different types of fibreoptic cable.

\begin{tabular}{|c|c|c|c|c|c|c|}
\hline & \multicolumn{4}{|c|}{ When fibre will be implemented horizontally } & \multirow[t]{2}{*}{ Total } \\
\hline & & Already & $\begin{array}{l}\text { Within } 6 \\
\text { months }\end{array}$ & $\begin{array}{l}6 \text { months } \\
\text { to } 1 \text { year }\end{array}$ & 1 year + & \\
\hline \multirow{4}{*}{$\begin{array}{l}\text { When fibre } \\
\text { will be } \\
\text { implemented } \\
\text { vertically }\end{array}$} & Already & 108 & 3 & 9 & 68 & 188 \\
\hline & $\begin{array}{l}\text { Within } 6 \\
\text { months }\end{array}$ & 3 & 26 & 4 & 4 & 37 \\
\hline & $\begin{array}{l}6 \text { months } \\
\text { to } 1 \text { year }\end{array}$ & 8 & 1 & 25 & 5 & 39 \\
\hline & 1 year + & 15 & 4 & 0 & 88 & 107 \\
\hline \multicolumn{2}{|l|}{ Total } & 134 & 34 & 38 & 165 & 371 \\
\hline
\end{tabular}

Table 1: Anticipated implementation time of vertical and horizontal fibre

One possible explanation is that the installation is new, and consequently all cabling will be installed simultaneously. This is unlikely, as the annual IT budgets and network sizes described above indicate established companies.

Another possibility is that organisations often upgrade their vertical and horizontal networks at the same time in order to minimise total disruption. The interview data suggest that IT professionals feel it is cheaper and easier to install fibre to upgrade vertical and horizontal cable at the same time. Converting from copper to fibre for horizontal cabling results in disruption, not only because cabling must be installed in work areas but because network devices need to be upgraded to be able to connect to the fibre.

In the words of one interviewee, "network connectivity may be disrupted and it is far better to only have the disruption once". Another, involved in rewiring of a building at 
the time of the interview, noted "you don't have to worry about it any more". A further suggestion was that "management don't want to make the same decision three months down the road. [Doing it all at once] saves wasting time". The implication here is that disruption to the network is not the only factor - disruption can also be extra work in the decision making process.

The concern here is that the decision to install fibre for horizontal links appears to be justified with an assumption that that it will be needed eventually. Two risks arise from this. First is that fibre may not be necessary for horizontal links for the lifetime of the network, in which case the expenditure was unnecessary. If bandwidth is the basis for the assumption that fibre is inevitable, it is possible that fibre may not be necessary during the life of the network, given that various standards to transmit data at up to 10 Gbps over various copper cable types are currently being developed.

Secondly, the type of fibre installed may be inappropriate when the future requirements emerge. Decision makers should be aware of these risks when making the decision to install horizontal fibre.

\section{Reasons for using vertical and horizontal fibre}

Similarly, there is a correlation between the reasons given for use of fibreoptic media in horizontal cabling, and for its use in vertical cabling. When the reasons for using fibre for vertical cabling are the dependent variable, $\lambda=0.252(\mathrm{p}=0.000)$. Analysing this relationship further using the cross-tabulation below reveals that there is likelihood that organisations will cite the same reason for the installation of fibre for vertical and horizontal cabling. 


\begin{tabular}{|l|l|c|c|c|c|c|c|}
\hline \multicolumn{2}{|c|}{} & \multicolumn{5}{|c|}{ Why use fibre for horizontal cabling } & Total \\
\cline { 3 - 8 } & $\begin{array}{c}\text { Future } \\
\text { expansion }\end{array}$ & EMI* & Distance & $\begin{array}{c}\text { Speed, } \\
\text { reliability } \\
\text { and } \\
\text { security }\end{array}$ & Other & \\
\hline $\begin{array}{l}\text { Why use } \\
\text { fibre for } \\
\text { vertical } \\
\text { cabling }\end{array}$ & $\begin{array}{l}\text { Future } \\
\text { expansion }\end{array}$ & 48 & 6 & 12 & 37 & 2 & 105 \\
\cline { 2 - 8 } & EMI* & 2 & 3 & 5 & 0 & 0 & 10 \\
\cline { 2 - 8 } & $\begin{array}{l}\text { Distance } \\
\text { Speed, } \\
\text { reliability } \\
\text { and } \\
\text { security }\end{array}$ & 25 & 3 & 21 & 108 & 0 & 157 \\
\cline { 2 - 8 } & Other & 1 & 9 & 44 & 29 & 1 & 98 \\
\hline Total & 91 & 21 & 82 & 174 & 3 & 371 \\
\hline
\end{tabular}

*Copper cable is susceptible to Electromagnetic Interference (EMI), while fibre is immune.

Table 2: Reasons for using fibre

The most common reason cited was providing for speed, reliability and security. Curiously, the number of responses that use horizontal fibre for this reason $(47 \%)$ was slightly greater than for vertical fibre $(42 \%)$. Future-proofing the network was the second-most common reason, with $28 \%$ of organisations citing this as the reason for using vertical fibre, and $25 \%$ giving this as the reason for using fibre horizontally.

While different applications may have different characteristics, specific applications do not figure highly in respondents' rationales for using fibre. This is reasonable when one considers that applications do not directly determine what physical layer is appropriate. Rather, applications determine particular communication requirements, effectively an aggregate of applications' requirements. Thus, applications are implicitly included in respondents' rationales. As well as transfer rates, some of which are suggested for example in Table 3, applications may have other specific requirements such as security or latency. 


\begin{tabular}{|l|l|}
\hline Application & Recommended minimum transfer rates \\
\hline Email & $2.4 \mathrm{Kbps}$ \\
\hline Digital voice, freeze-frame video & $64 \mathrm{Kbps}$ \\
\hline Database text query & $\mathrm{Up}$ to $1 \mathrm{Mbps}$ \\
\hline Stereo audio & $1-2 \mathrm{Mbps}$ \\
\hline Broadcast-quality video & $120 \mathrm{Mbps}$ \\
\hline
\end{tabular}

Table 3: Recommended minimum transfer rates of selected common applications

Source: Housel and Skopec (2001)

In turn, such communication requirements determine which networking technologies and which media are appropriate. Some requirements do not affect the Physical Layer specifically; Quality of Service requirements for example are a characteristic of higher layers and not a function of the media itself. Further, it is likely that multiple technologies and multiple cable types are able to satisfy an organisation's communication requirements.

The correlation between rationales for vertical and horizontal fibre could indicate that networks are relatively homogenous, and that cabling criteria are largely consistent throughout the network. This offers an explanation for the above, that fibre is implemented horizontally and vertically at about the same time - if the same criteria apply for both backbone and horizontal cabling, fibre will be needed for one if it is needed for the other. However, it is intuitively unlikely that the same bandwidth, futureproofing and distance requirements that exist on the backbone will exist in horizontal cable runs.

Another, albeit unflattering, possibility is that IT personnel do not think too deeply about selecting the cable type and simply apply the same rationale, regardless of the particular characteristics of the network being upgraded. This is supported by a comment from one interviewee, "I think a lot of the time fibre may be installed simply because it is look upon (sic) as being the most high speed and so the best".

Other interviewees suggested that in situations where the staff that make the recommendation are not the same as those responsible for the decision, information will often be provided so as to persuade the decision maker. Likewise, vendors will naturally be as persuasive as possible when providing information about their products. 
Thus, decision makers will respond to survey questions about why they have installed fibre with the rationale that succeeded in persuading them in, rather than with information specific to their requirements. As one interviewee observed, they may not know much, other than what they have been told. In the words of one interviewee, the key thing for decision makers is being able to "smell the bullshit" when assessing information about installation about fibre. It is noted that if decision makers had access to information about which cable types would be widely supported in the future, they would be less vulnerable to manipulation.

Further research is required into the differences in perception between staff who influence decisions and decision makers in order to examine this hypothesis. It is also noted that the survey from which the current data were collected did not distinguish speed, reliability and security as reasons for adopting fibre. Future research will address this shortcoming.

\section{Implementation time of vertical fibre and wireless networking}

A correlation was found between the timing of the implementation of fibre for vertical cabling and the timing of the implementation of wireless networking. Using the implementation time of wireless networking as the dependent variable, $\lambda=0.233$ $(p=0.000)$. A tendency to implement the two at the same time was discovered.

\begin{tabular}{|l|l|c|c|c|c|c|}
\hline \multicolumn{2}{|c|}{} & \multicolumn{2}{|c|}{ When wireless networking will be implemented } & \multirow{2}{*}{ Total } \\
\cline { 3 - 7 } \multicolumn{2}{|c|}{} & Already & $\begin{array}{c}\text { Within 6 } \\
\text { months }\end{array}$ & $\begin{array}{c}6 \text { months } \\
\text { to 1 year }\end{array}$ & 1 year + & \\
\hline $\begin{array}{l}\text { When fibre } \\
\text { will be } \\
\text { implemented } \\
\text { vertically }\end{array}$ & Already & 94 & 19 & 27 & 48 & 188 \\
\cline { 2 - 7 } & $\begin{array}{l}\text { Within 6 } \\
\text { months }\end{array}$ & 7 & 18 & 3 & 9 & 37 \\
\cline { 2 - 7 } & $\begin{array}{l}\text { 6 months } \\
\text { to 1 year }\end{array}$ & 13 & 8 & 9 & 9 & 39 \\
\cline { 2 - 7 } & 1 year + & 21 & 6 & 15 & 65 & 107 \\
\hline \multicolumn{2}{|l|}{ Total } & 135 & 51 & 54 & 131 & 371 \\
\hline
\end{tabular}

Table 4: Anticipated implementation time of vertical fibre and wireless LAN 
Two interviewees expressed surprise at this relationship, and commented that having fibre installed in the backbone indicates a need for fast network communications, while wireless is up to 10 times slower than an average copper-wired LAN. Thus, installing a wireless network is inconsistent with installing a fibre backbone, at least as far as obtaining a fast network is concerned.

One explanation may be that size of organisation drives both the use of fibre and wireless adoption. However, the relationship between the independent variable - size of network (measured as the number of network points in use) - and the dependent variable - vertical fibre adoption time - was weak $(\lambda=0.142, p=0.000)$. Further, the size of the network has an even weaker effect on the decision to adopt wireless $(\lambda=0.123, \mathrm{p}=0.004)$. Given the lack of a strong relationship between network size and either vertical fibre or wireless adoption, other reasons must be found.

It may be that implementation of wireless networking is done at the same time as upgrading the backbone to fibre in order to reduce disruption. However, this argument appears questionable, a point observed by one interviewee: "I don't think a wireless LAN is very disruptive to install at all, especially when compared to installing a fibre backbone".

Another possibility is that organisations tempted to consider newer technologies such as wireless will also be using more advanced technology in other areas, hence the adoption of fibre for their backbone.

One interviewee commented that wireless networks are also often operated in parallel to wired infrastructure, and the requirements, as determined by the applications that operate over each network segment, may be different. However, the survey data do not show the extent to which this occurs. Given that wireless networking is relatively new, it is perhaps too early to say whether it will replace horizontal cable. Further investigation is required to determine the factors that drive wireless adoption, and whether the adoption of wireless networking is influenced by vertical cable selection.

Main backbone in five years and choice of fibre 
Not surprisingly, there is a correlation between the independent variable of the cable believed to be dominant in five years' time, and the dependent variable of choice of fibre that is either currently installed or planned to be installed $(\lambda=0.266, p=0.000)$. The majority of respondents who expected single mode fibre would be dominant had installed single mode, and likewise for 50 micron and 62.5 micron multimode.

\begin{tabular}{|l|l|c|c|c|c|}
\hline \multicolumn{2}{|c|}{} & \multicolumn{3}{|c|}{ Which fibre } & Total \\
\cline { 3 - 6 } \multicolumn{2}{|c|}{} & $\begin{array}{c}\text { Single- } \\
\text { mode }\end{array}$ & $\begin{array}{c}50 \text { micron } \\
\text { multimode }\end{array}$ & $\begin{array}{c}62.5 \text { micron } \\
\text { multimode }\end{array}$ & \\
\hline \multirow{2}{*}{$\begin{array}{l}\text { Main } \\
\text { backbone in } \\
\text { five years }\end{array}$} & Single-mode & 47 & 15 & 25 & 87 \\
\cline { 2 - 6 } & $\begin{array}{l}50 \text { micron } \\
\text { multimode }\end{array}$ & 22 & 61 & 21 & 104 \\
\cline { 2 - 6 } & $\begin{array}{l}62.5 \text { micron } \\
\text { multimode }\end{array}$ & 11 & 28 & 46 & 85 \\
\cline { 2 - 6 } & Cat 5e & 6 & 4 & 3 & 13 \\
\cline { 2 - 6 } & Cat 6 & 20 & 10 & 6 & 36 \\
\cline { 2 - 6 } & Cat 7 & 13 & 18 & 11 & 42 \\
\cline { 2 - 6 } & Other & 120 & 138 & 113 & 371 \\
\hline \multicolumn{1}{|c|}{ Total } & & 12 & 2 & 1 & 4 \\
\hline
\end{tabular}

Table 5: Perception of the main backbone in five years and choice of fibre

However, there were still sizable proportions of responses that had chosen to implement something other than the cable they currently considered would be dominant in five years' time. $46 \%$ of those who expected single mode fibre to be dominant had installed multimode fibre, $41 \%$ of those who expected 50 -micron multimode to be dominant had installed either single mode or 62.5 -micron multimode, and $46 \%$ of those who anticipated 62.5-micron multimode to win out had installed either single mode or 50-micron multimode. Further, $25 \%$ of responses even believed that copper cable (Cat5e, Cat6 or Cat7) would be dominant, and yet had opted to install fibreoptic cable themselves.

A number of possibilities for these results arise. First, some organisations may anticipate certain media becoming dominant, but they may not feel that this is important when selecting network media for their own use. However, all interviewees unanimously rejected this. 
Another suggestion is that many organisations have installed a particular fibre type and that their perceptions of the likely dominant backbone have changed in the interim. This could highlight the difficulty in selecting cable, a point noted by one interviewee: "If possible, it is always preferable to install the longer lasting technology, [but] it is sometimes difficult to predict where technology will be heading". The cable planning model proposed in this paper would help avoid such a problem by revealing which cable types are more likely to be in widespread use in the future.

Interviewees strongly held the belief that it is important to try to predict what type of cable would be dominant in the future, indicating the importance of the framework towards which this research is working.

Reasons for the use of fibre and which fibre is chosen

A weak relationship existed $(\lambda=0.103, p=0.004)$ where the reasons for using fibreoptic cable for the backbone (independent variable) helped predict the type of fibreoptic cable chosen (dependent variable). More 62.5 micron multimode users cited distance and bandwidth requirements as the reason for adopting fibre for the backbone, while the most popular reason for organisations using single mode and 50 micron multimode fibre was to provide speed, reliability and security.

The association of distance with 62.5 micron multimode fibre is peculiar, given that 62.5 micron multimode can sustain only comparatively short distance runs of $220 \mathrm{~m}$ at gigabit speeds, while 50 micron multimode can support up to 500m (IT Cabling Solutions, 2000). Single mode fibre can sustain even greater distances than multimode.

\begin{tabular}{|l|l|c|c|c|c|}
\hline \multicolumn{2}{|c|}{} & \multicolumn{3}{|c|}{ Which fibre } & \multirow{2}{*}{ Total } \\
\cline { 3 - 5 } \multicolumn{2}{|c|}{} & $\begin{array}{c}\text { Single- } \\
\text { mode }\end{array}$ & $\begin{array}{c}50 \text { micron } \\
\text { multimode }\end{array}$ & $\begin{array}{c}62.5 \text { micron } \\
\text { multimode }\end{array}$ & \\
\hline \multirow{2}{*}{$\begin{array}{l}\text { Why use } \\
\text { fibre for the } \\
\text { backbone }\end{array}$} & $\begin{array}{l}\text { Future } \\
\text { expansion }\end{array}$ & 35 & 45 & 25 & 105 \\
\cline { 2 - 5 } & EMI & 4 & 6 & 0 & 10 \\
\cline { 2 - 5 } & Distance & 27 & 24 & 47 & 98 \\
\cline { 2 - 5 } & $\begin{array}{l}\text { Speed, } \\
\text { reliability and } \\
\text { security }\end{array}$ & 53 & 63 & 41 & 157 \\
\hline
\end{tabular}




\begin{tabular}{|l|l|c|c|c|c|}
\hline & Other & 1 & & & 1 \\
\hline Total & 120 & 138 & 113 & 371 \\
\hline
\end{tabular}

Table 6: Reasons for a fibre backbone and choice of fibre

That this is only a weak relationship is perhaps explained by the observations of one interviewee, that cost and the expected lifetime of the technology are important criteria when choosing between fibre types. The survey data only report the reasons for use of fibre overall, not for the use of one fibre type over another. Further research to examine this in more detail is required.

\section{CONCLUSIONS}

Communications electronics become obsolete within three to five years, while the communication cabling itself has a considerably longer lifespan, up to 10 years (Qayoumi, 1995) or even 15 years (Phan, 2001). Clearly, if cabling will significantly outlive the devices connected to it, structured cabling systems should use cabling that will be able to be used by future devices not yet on the market.

However, there is currently there is no clearly preferred medium, at least in the opinion of IT professionals in Asia. 21\% of survey respondents believed that in five years the dominant backbone would be either Cat 6 or Cat7. Fibre also had its proponents $-28 \%$ believed 50 micron multimode fibre would be dominant, and $23 \%$ believed 62.5 micron multimode fibre would be dominant. $23 \%$ also believed single mode fibre would emerge as the most common.

While there may be technologically "correct" answers to many of these questions, technology does not diffuse according to technological superiority. Rather, technology diffusion is a function of the information available in the marketplace (Geroski, 2000). Thus, reducing the risk inherent in decision-making when investing in technology involves an element of guesswork - if a new technology is chosen which, while technically superior, does not diffuse through the market, future support for that technology will be lacking. 
Thus, in order to extend the lifespan of technology it is useful to consider whether that technology is likely to be widely adopted. This requires understanding what drives individuals or organisations to choose to adopt it, whether such decisions are technically sound or not.

The cable planning model proposed in this paper will be applied to data about the industry in general and provide a clearer picture of the cable types that are likely to become dominant in the market. This will facilitate organisations extending the lifespan of their infrastructure as described above.

This research has determined a number of relationships between factors in the cable selection decision process. Development of a statistical model based on these, and perhaps as yet undiscovered relationships, will facilitate widespread analysis of the market and thus to make projections about likely cable adoption in the future. In assessing which cable technologies are likely to become widespread in the future, organisations can reduce the potential error in cable selection decisions.

Another finding emerging from this research is that the decision to implement fibre for horizontal cabling appears often to be based on the assumption that fibre will inevitably be required. The danger is that such an assumption appears to be based on little analysis, if any, and further does not distinguish between the different types of fibre available today.

It is concerning that such decisions are made without much consideration - "[you] don't think about it very much", as one interviewee expressed it. This allows decision makers to be manipulated by others who may not be motivated by the organisation's best interests.

That this assumption may be incorrect raises the possibility that organisations may be installing the wrong type of fibre, or even installing fibre unnecessarily - a costly and disruptive outcome. Decision makers opting to install fibre should ensure that they are not making such a mistake by checking the validity of their assumptions. 
Finally, this paper has suggested the need for further research to determine whether the following relationships are statistically significant, and if so, what drives them:

- The implementation of vertical and horizontal fibre at the same time;

- Why the same reasons are given for the installation of vertical and horizontal fibre, despite having intuitively different requirements;

- Whether the decision to adopt wireless networking is influenced by the choice of vertical infrastructure;

- How perceptions of the future affect the selection of fibre over other media;

- How factors such as distance and bandwidth requirements affect the choice of fibre.

Such research will further develop the model proposed in this paper, allowing better infrastructure decision-making.

\section{REFERENCES}

Choi, S.Y. \& Whinston, A.B. (2000) Benefits and requirements for interoperability in the electronic marketplace, Technology in Society 22(1), 33-44.

Clark, C. (2002) Network Cabling Handbook, McGraw-Hill/Osborne, Berkeley, CA, USA.

Feldman, J. (2001) Escaping Token Ring Without Losing Your Shirt or Mind, Network Computing, April 16.

Geroski, P.A. (2000) Models of technology diffusion, Research Policy 29, 603-625.

Groth, D., McBee, D. \& Barnett, D. (2001) Cabling: The Complete Guide to Network Wiring, Sybex. 
Housel, T.J. \& Skopec, E.W. (2001) Global Telecommunications Revolution, McGraw Hill, Singapore.

Inverso, J. (2001) Cable Management Systems and Software: Overview, Gartner Group, Note Number DPRO-89779, June 20.

IT Cabling Solutions (2000) The Complete Guide to Structured Cabling, Available from http://www.it-cabling-solutions.co.uk/html/structured_cabling/index.htm.

Low, G. (2003) Trends in Infrastructure Cabling in Asia, Curtin University of Technology, Australia.

Norušis, M.J. (1997) SPSS 7.5 Guide to Data Analysis, Prentice-Hall, Upper Saddle River, New Jersey, USA.

Phan, S. (2001) Practical Cabling, CMPnetAsia, August 1. Available from http://www.cmpnetasia.com/.

Qayoumi, M.H. (1995) Premises wiring: The architecture of communication, Facilities Design and Management 14(7) 60.

Tanenbaum, A.S. (2003) Computer Networks, Prentice Hall, Upper Saddle River, New Jersey, USA.

Vacca, J. (1999) The Cabling Handbook, Prentice Hall, Upper Saddle River, New Jersey, USA. 